\title{
Editorial
}

\section{Pontuações sobre qualidade, quantidade e temporalidade na clínica}

Sonia Leite*

O tema do nosso VII Congresso Internacional de Psicopatologia Fundamental e XIII Congresso Brasileiro de Psicopatologia Fundamental, "A questão da qualidade no método clínico", me fez lembrar do pensador francês Paul Virilio e de suas brilhantes articulações entre a técnica, a velocidade e a política, em seus impactos sobre os ritmos humanos na atualidade. Arquiteto e urbanista de formação sua obra tem dialogado com diversos campos de estudo tais como as artes visuais, as mídias, e as ciências ditas humanas, de um modo geral.

Em seu percurso, chama a atenção uma trajetória que se inicia pelo "estudo da organização dos espaços", no sentido próprio da arquitetura e do urbanismo, seguindo em direção ao "estudo do tempo" e, em particular, daquilo que denominou de tempo-velocidade na cultura contemporânea. Destaca, aqui, a aceleração do tempo que, segundo suas reflexões, tende a esgotar ou mesmo a desintegrar a ideia de espaço.

Considera que o tempo-velocidade vincula-se ao movimento da máquina-de-guerra mundial, ${ }^{1}$ efeito do capitalismo avançado, que induz a um estado de emergência que atravessa todo o tecido social. Parte da premissa de que é a partir da guerra, ou mesmo da preparação para

\footnotetext{
* Universidade do Estado do Rio de Janeiro - UERJ (Rio de Janeiro, RJ, Br).

${ }^{1} \mathrm{O}$ paradigma-máquina se refere à velocidade e está incorporada no agir social — exigimos velocidade das máquinas e dos corpos, corpos velozes, dinâmicos, aptos a atender às vicissitudes do capital.
} 
a guerra, que a civilização moderna e contemporânea acaba por criar um novo humanismo fundado na destruição. Tal constatação tem levado o autor a dedicar suas pesquisas, especialmente, em torno das relações fundamentais entre a ciência, a tecnologia e o poder militar.

Apesar da proposta, aqui, não ser a de discutir as ideias do filósofo, o que vale destacar é que ao articular velocidade, guerra e política, enquanto fruto da revolução da informação e do movimento de globalização, o autor introduz como princípio ético fundamental, para os problemas que permeiam a atualidade, a criação de interrupções na temporalidade instituída. Interrupção enquanto descontinuidade, suspensão, cessação que valoriza os encontros em sua singularidade. Tal perspectiva reporta a uma ética do sujeito e à reapropriação da experiência do espaço - que envolve o corpo próprio e o território — espaço que não é da ordem empírica, mas estruturado pela linguagem (Lacan, 1972-1973/1982).

A descrição feita pelo autor de uma dada hegemonia da temporalidade se reporta aos efeitos das ininterruptas demandas instituídas pelo discurso capitalista que, desde a era moderna, se traduz no "time is money", regulador das leis do consumo e do mercado.

O tempo-velocidade consome e desintegra a experiência do espaço comum, enquanto lugar de construção das trocas simbólicas. Todo o campo social se transforma, assim, em um campo de guerra, numa verdadeira militarização do cotidiano, título de um livro seu. Trata-se, aqui, de uma guerra não declarada que militariza e homogeneíza corpos e consciências. A guerra pura se traduz pelos investimentos representativos em tecnologia de destruição e controle, como por exemplo: armamentos militares, segurança privada, câmeras de vídeo, espionagem internáutica dentre outros, que instituem "modos de ser" e instauram lógicas de funcionamento social que, cada vez mais, independem das pessoas em sua particularidade.

Nesse sentido, quando nos convoca às interrupções, o filósofo revaloriza o campo simbólico onde vigora o uso da palavra, mas também o insabido como marca do real (Lacan, 1971-1972). A quebra da hegemonia do tempo-velocidade introduz a descontinuidade própria ao sujeito desejante permitindo o aparecimento de outras modalidades temporais e da reapropriação do espaço coletivo.

Freud (1929/2007), no artigo "O mal-estar na civilização”, já havia criticado a ideia ilusória de progresso destacando o grande paradoxo que é a problemática do desejo na cultura. Longe de fazer uma proposta visando a harmonia ou mesmo a adaptação do indivíduo à sociedade, o que destaca é a imensa tarefa à qual somos todos convocados, no sentido do trabalho psíquico, o que inclui a criação de estratégias capazes de viabilizar que um tanto de felicidade possa ser desfrutada ao longo da existência.

Lacan, por sua vez, como resposta aos acontecimentos de maio de 1968 introduz no seminário 17 (1969-1970/1992) os quatro discursos (discurso do 


\section{EDITORIAL}

mestre, discurso da histérica, discurso do universitário, discurso do analista) para abordar a temática dos laços sociais. Trata-se de um importante instrumento conceitual para pensar a ação do psicanalista no socius e a aposta no desejo, temática introduzida num momento histórico em que o mal-estar na cultura se acentuava. Mais adiante, inventa a escrita do discurso do capitalista para indicar que algo aí caminha sobre rodas, ou seja, que anda rápido demais, que se consome tão bem até o ponto em que se consuma (Lacan, 1972).

Destaca, assim, a ideia de "consumismo" e "consumição" apontando um sistema que favorece tanto o consumo exagerado quanto o ato de consumir-se, mortificar-se. Em outras palavras, os gadgets, as quinquilharias e as demandas de consumo em geral deixam as pessoas completamente à mercê dos objetos, à deriva e impossibilitadas de exercer, de fato, suas escolhas.

Tais reflexões importam para a temática da qualidade na clínica na medida em que o tempo-velocidade, implicado no discurso do capitalista, tem como efeito um imperativo que exige tanto a "resposta pronta", do profissional que trabalha com a saúde, quanto o "pronto restabelecimento" do sujeito em sofrimento, cuja visada é o imediato retorno à nossa guerra cotidiana. Em outras palavras, as relações sociais atravessadas por uma infinidade de demandas acabam, muitas vezes, por impedir o tempo necessário à simbolização da experiência do adoecer, do sofrimento, atropelando-se o que há de mais singular na existência.

\section{A medicina e as evidências}

Nesse sentido, num importante artigo de 1966, denominado "O lugar da psicanálise na medicina", Lacan alerta a respeito da presença hegemônica do discurso cientificista na cultura, situando as transformações históricas na função do médico e no papel da psicanálise nesse contexto.

Com os avanços da ciência, considera que a tradicional posição simbólica do médico tem sido diluída restringindo-se a ser uma simples agência distribuidora dos aparatos desenvolvidos pelos avanços tecnológicos. Assim, pouco a pouco, se subtrai um lugar privilegiado de suposição de saber estabelecido para o médico e que sustenta o fenômeno da transferência. Esse estreitamento do fazer clínico não é sem consequências qualitativas.

Com a expansão do poder da ciência, aliado aos avanços do capitalismo se, por um lado, estabelece-se o direito ao chamado acesso à saúde, por outro, tende-se a produzir uma verdadeira banalização da temática, transformando-se esse direito em mais uma mercadoria a ser adquirida, ou, como indica Lacan, em mais um ticket beneficio a ser buscado pelo consumidor. Essa perspectiva 
transforma não apenas o lugar do médico, e da clínica, mas produz uma verdadeira dissolução da função que passa, então, a ser ocupada pelos inúmeros peritos da saúde, que dividem com o médico o posto de intermediários e distribuidores dos produtos da ciência.

$\mathrm{Na}$ atualidade, tanto a medicina curativa quanto a medicina pautada nos cuidados paliativos tem se servido dos resultados da chamada Medicina Baseada nas Evidências (MBE). Trata-se de um movimento que surge na década de 1990, ligado à epidemiologia clínica anglo-saxônica que tem, cada vez mais, definido o fazer clínico em geral. A MBE se define como fundamentada na capacidade de analisar criticamente a informação científica e aplicá-la de forma racional a fim de aprimorar a qualidade da assistência médica (El Dib, 2007). A visada, em última instância, é a aplicação de resultados da pesquisa científica quantitativa na prática clínica.

A palavra evidência tem aqui algumas significações que valem a pena ser destacadas: efetividade, eficiência, eficácia e segurança. A proposta é evitar a ocorrência de efeitos indesejáveis ou imprevisíveis, do ponto de vista do tratamento. Tudo isso envolve na clínica a rapidez no uso de determinados procedimentos protegendo tanto os médicos quanto os pacientes da intromissão de aspectos indesejáveis, tais como sentimentos, desejos, resistências, dúvidas (Pereira, 2015). Tal rapidez, muitas vezes, acaba por excluir o sujeito, enquanto sujeito da enunciação, e seus ritmos próprios.

\section{O sujeito e a temporalidade}

Publicado pela primeira vez em 1945, quando finda a Segunda Guerra Mundial, o texto lacaniano "O tempo lógico e a asserção da certeza antecipada um novo sofisma", só chegará aos leitores em 1966. É a diversidade dos modos temporais, presentes na constituição do sujeito, que Lacan sublinhará nesse complexo trabalho.

O tempo lógico, em suas três modulações - instante de ver, tempo para compreender e momento de concluir — não se constitui numa linearidade. O que Lacan demonstra com seu sofisma é "que a instância tempo se apresenta de um modo diferente em cada um desses momentos (...) revelando neles uma descontinuidade tonal, essencial para seu valor" (1945/1998, p. 204). Valor que marca a definição de sujeito do inconsciente em sua distinção em relação ao conceito de indivíduo, unidade estatística, universal, própria ao campo da epidemiologia clínica (Brant, 2001).

Seguindo a premissa freudiana de que o funcionamento do inconsciente é atemporal, Lacan, mais adiante em 1964, vai defini-lo como pulsação, ritmo que produz uma abertura e um fechamento. Abertura que se expressa, exatamente 
na emergência do sentido novo. Fechamento, enquanto ato conclusivo, que acompanha a constituição do sentido que emerge, por exemplo, quando uma pontuação finaliza uma frase. Isso indica que o sentido sempre se faz no a posteriori, num tempo do só depois. Ele é retroação sobre o discurso do sujeito. Momento quando se conclui uma frase ou mesmo uma consulta. No mesmo dia, ou após vários dias em um novo encontro clínico. O que emerge é o próprio sujeito, na surpresa da experiência e na descoberta de algo.

O significante "evidência" tem, de fato, uma relação com o instantâneo que parte do achatamento do tempo de compreender, descrito por Lacan (apud Costa, 2011). O ver se torna, assim, idêntico ao saber instituindo um curto circuito no tempo. O que se exclui é o sujeito da dúvida e a possibilidade de instauração da transferência necessária ao exercício da clínica.

Sem desconsiderar a importância das pesquisas quantitativas para a prática médica a questão que se coloca é que a temática da qualidade depende da singularidade do encontro clínico e da constituição de uma temporalidade que viabilize a emergência do sujeito. Em outras palavras, a clínica, "contém uma lógica que se revela pela narrativa construída pelo médico e o paciente (...)" (Berlinck, 2009).

$\mathrm{O}$ tratamento - seja qual for a dor que se apresente — depende sempre de um processo concomitante de responsabilização do sujeito, não se limitando, portanto, ao instante da evidência, universalizado pelas pesquisas médicas científicas. Tal responsabilização, por sua vez, é tributária de um tempo de elaboração que se conclui num ato de decisão que corresponde a uma escolha do sujeito em sofrimento.

\section{Referências}

Berlinck, M.T. O método clínico: fundamento da psicopatologia. Editorial. Revista Latinoamericana de Psicopatologia Fundamental, 12(3), 441-444, set. 2009.

Brant, L.C. O indivíduo, o sujeito e a epidemiologia. Revista Ciência e Saúde Coletiva, 6(1), 221-223, 2001.

Costa, A.M.M. Sobre o saber na pesquisa e intervenção no campo social. In H. Caldas, S. Altoé, Psicanálise, Universidade e Sociedade. Rio de Janeiro: Cia de Freud, 2011.

El Dib, R.P. Como praticar a medicina baseada em evidências. Jornal Vascular Brasileiro, 6(1), 1-4, 2007.

Freud, S. (2007). El malestar en la cultura. In Obras completas. Buenos Aires: Amorrortu. (Trabalho original publicado em 1930[1929]).

Lacan, J. (1966). O lugar da psicanálise na medicina. Revista Opção Lacaniana, 32, 8-14, dez. 2001.

Lacan, J. (1971-1972). O saber do psicanalista. Inédito. 
Lacan, J. (1972). O discurso psicanalítico. Inédito.

Lacan, J. (1982). O seminário. Livro 20. Mais, ainda. Rio de Janeiro: Jorge Zahar. (Trabalho original publicado em 1972-1973).

Lacan, J. (1992). O seminário. Livro 17. O avesso da psicanálise. Rio de Janeiro: Jorge Zahar. (Trabalho original publicado em 1969-1970).

Lacan, J. (1993). O seminário. Livro 11. Os quatro conceitos fundamentais da psicanálise. Rio de Janeiro: Jorge Zahar. (Trabalho original publicado em 1964).

Lacan, J. (1998). O tempo lógico e o sujeito da certeza antecipada - um novo sofisma. In: Escritos. Rio de Janeiro: Jorge Zahar. (Trabalho original publicado em 1945).

Leite, S.C. (2015). Emergência psiquiátrica: o que se aprende e o que se trata? In: V.A. Darriba, R.M. Manso (Orgs.). Psicanálise e Saúde: entre o Estado e o Sujeito. Rio de Janeiro: Cia. de Freud, 2015.

Pereira, L.R. (2015). Uma experiência de clínica psicanalítica em hospital oncológico. Dissertação de Mestrado. Programa de Pós-Graduação em Psicanálise, Universidade do Estado do Rio de Janeiro, Rio de Janeiro.

Virilio, P. (1983). Guerra pura - a militarização do cotidiano. São Paulo: Brasiliense.

Citação/Citation: Leite, S. (2015, setembro). Editorial. Pontuações sobre qualidade, quantidade e temporalidade na clínica. Revista Latinoamericana de Psicopatologia Fundamental, $18(3), 425-430$.

Editores do artigo/Editors: Prof. Dr. Manoel Tosta Berlinck e Profa. Dra. Sonia Leite

Recebido/Received: 15.7.2015/ 7.15.2015 Aceito/Accepted: 25.7.2015 / 7.25.2015

Copyright: (C) 2009 Associação Universitária de Pesquisa em Psicopatologia Fundamental/ University Association for Research in Fundamental Psychopathology. Este é um artigo de livre acesso, que permite uso irrestrito, distribuição e reprodução em qualquer meio, desde que o autor e a fonte sejam citados / This is an open-access article, which permits unrestricted use, distribution, and reproduction in any medium, provided the original authors and sources are credited.

\section{Sonia Leite}

Psicanalista; Membro do Corpo Freudiano Escola de Psicanálise (Rio de Janeiro, RJ, Br); Doutora em Psicologia Clínica pela Pontifícia Universidade Católica do Rio de Janeiro PUC-Rio (Rio de Janeiro, RJ, Br); Coordenadora Adjunta da Residência Multiprofissisonal em Saúde Mental SES-RJ/UERJ (Rio de Janeiro, RJ, Br); Editora da Revista Latinoamericana em Psicopatologia Fundamental; Membro da Associação Universitária de Pesquisa em Psicopatologia Fundamental - AUPPF (São Paulo, SP, Br); autora do livro Angústia da coleção Passo a Passo da Jorge Zahar Ed. e de diversos artigos. Rua Conde de Bonfim, 232/712 20520-051 Rio de Janeiro, RJ, Br. e-mail: soniacleite@uol.com.br 